\title{
EU trade agreements and the sugar sector
}

\author{
Ellen Huan-Niemi \\ MTT Economic Research, Luutnantintie,00410 Helsinki.ellen.huan-niemi@mtt.fi
}

Presently, the EU is engaged in enlarging and negotiating or implementing trade agreements, which are unilateral, bilateral, regional and multilateral in nature. The common market organisation (CMO) of sugar is a good example of the interactions between the different trade agreements (Figure).

Figure. The EU sugar regime and trade agreements.

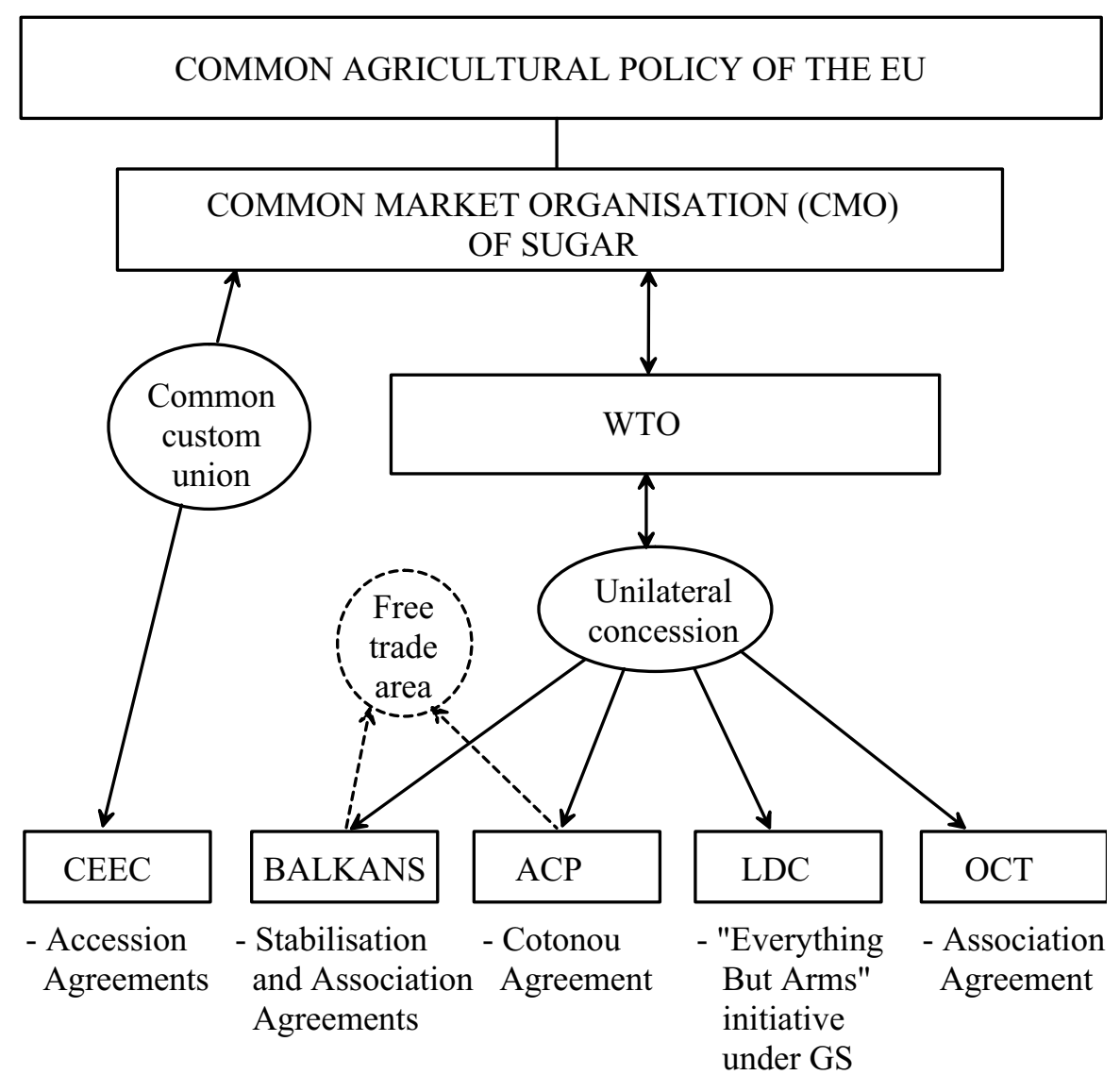

Under EU enlargement, ten new member states are joining the EU in year 2004, consisting of Poland, Hungary, Czech Republic, Slovenia, Estonia, Latvia, Lithuania, Slovakia, Cyprus and Malta. Bulgaria and Romania are expected to join the EU by year 2007. Sugar production quotas will be imposed on the new member states by the EU Commission after EU enlargement. The sugar production quotas agreed between the Central and Eastern European (CEE) countries and the EU Commission are below the initial requests by the CEE countries. The overall EU sugar production quotas will increase by 2.96 million tons in year 2004 and an estimated 3.22 million tons in year 2007 (Table). In the first wave of enlargement, the CEE countries will be producing more quota sugar than consumption with quota production exceeding consumption by nearly 50 thousand tons. However, according to the rules specified by the EU Commission, the sugar consumption of Bulgaria and Romania will exceed their entitlement of quota sugar production. In fact, the CEE countries' sugar consumption will exceed quota sugar production by an estimated 430 thousand tons in year 2007. As a consequence, the accession of the CEE countries will not be a burden on the EU sugar regime.

Under the WTO rules, third countries have to be compensated for their market access in the countries that are joining a common custom union like the EU, if the "current access" of the third countries in the markets of the accession countries is jeopardised due to the common custom union. The CEE countries are currently importing sugar not only from the EU member states and candidates, but also from third countries like Brazil, Guatemala, Nicaragua, Mexico, Cuba, and Australia. Current 
access quotas are allocated to Brazil, Cuba and other third countries after the accession of Finland, Austria, and Sweden in $1995^{1}$. The EU has undertaken to import 85,463 tons of raw sugar as part of its "current access" commitment due the agreement under GATT ${ }^{2}$. As a result, the EU has to either allocate "current access" quotas for sugar imports from Brazil, Guatemala, Nicaragua, Mexico, Cuba, and Australia or compensate these countries in other ways like market access in other EU markets or compensatory payments to these countries. The potential "current access" quotas for third countries is estimated to be about 490 thousand tons in the enlarged EU sugar regime by including Bulgaria and Romania (Table). Overall, the CEE countries' sugar consumption that exceed quota production will be matched by the allocation of potential "current access" quotas for third countries' historical market access in the sugar markets of the CEE countries. If the "current access" of third countries is compensated in other ways than allocating sugar import quotas, the "additional consumption" from the CEE countries will alleviate the current overproduction pressures in the current EU-15 member states.

Table. Central and Eastern European Countries' sugar production quotas, consumption and potential "current access" for third countries.

\begin{tabular}{|c|c|c|c|c|c|c|}
\hline- & A quotas & B quotas & $\begin{array}{l}\text { Total quotas } \\
\text { (Production) }\end{array}$ & $\begin{array}{l}\text { Total } \\
\text { Consumption }\end{array}$ & \begin{tabular}{|l|} 
Production \\
minus \\
Consumption \\
\end{tabular} & \begin{tabular}{|l} 
Potential \\
"current access" \\
for third countries
\end{tabular} \\
\hline Czech Rep. & 441209 & 13653 & 454862 & 441409 & 13453 & \\
\hline Estonia* & nil & nil & nil & 50000 & -50000 & \\
\hline Hungary & 400454 & 1230 & 401684 & 378791 & 22893 & \\
\hline Latvia & 66400 & 105 & 66505 & 70000 & -3495 & 11410 \\
\hline Lithuania & 103010 & nil & 103010 & 96241 & 6769 & \\
\hline Poland & 1580000 & 91927 & 1671927 & 1590533 & 81394 & \\
\hline Slovakia & 189760 & 17672 & 207432 & 195000 & 12432 & \\
\hline Slovenia & 48157 & 4816 & 52973 & 87000 & -34027 & 2875 \\
\hline Bulgaria** & 7000 & 700 & 7700 & 206000 & -198300 & 196345 \\
\hline Romania** & 225000 & 25500 & 250500 & 532000 & -281500 & 278049 \\
\hline TOTAL & 3060990 & 155603 & 3216593 & 3646974 & -430381 & 488679 \\
\hline $\begin{array}{l}\text { TOTAL } \\
\text { excluding } \\
\text { Bulgaria \& } \\
\text { Romania }\end{array}$ & 2828990 & 129403 & 2958393 & 2908974 & 49419 & 14285 \\
\hline
\end{tabular}

Source: CEC 2002, EUROSTAT COMEXT, FAOSTAT, Interactive TradeMap, PC-TAS.

* Estonia, Malta, and Cyprus do not produce sugar, therefore, the EU Commission did not allocate sugar production quotas to these countries.

** Production quotas and consumption figures are estimated according to the EU Commission's rules.

*** Historical quantities of sugar imported by the CEE countries are potential "current access quotas" for countries outside the EU after enlargement.

\footnotetext{
${ }^{1}$ Commission Regulation (EC) No $1507 / 96$ of 29 July 1996 opening and providing for the administration of certain tariff import quotas for the supply of raw cane sugar to Community refineries.

${ }^{2}$ General Agreement on Tariff and Trade
} 
The reform of the EU sugar regime will affect not only the EU member states and candidates, but also countries that are associated with the EU through the preferential, regional, and multilateral trade agreements. For several decades, the EU has supported and protected the EU sugar sector. Sugar from developing countries will not be able to enter the EU sugar market without preferential trade agreements. In the EU sugar regime, the unique features of the trade concessions are that sugar under preferential import quotas can enter the EU market duty free and the price paid for sugar equals to the high EU price for sugar.

One crucial issue for the African, Caribbean and Pacific (ACP) countries is whether the EU will continue the ACP/EU Sugar Protocol after the end of the Cotonou Agreement in 2008. Although, the Sugar Protocol explicitly states that the EU undertakes for an "indefinite period" to purchase and import, at guaranteed prices, specific quantities of cane sugar which originate from the ACP countries. But, the EU Commission is currently examining options for reforming the sugar regime, most of which involve substantial cuts in the EU's guaranteed price for sugar. For instance, the ACP countries' income from sugar exports will be reduced by more than EUR 200 Million per year with a $25 \%$ cut in the EU sugar intervention price. The worst scenario for the ACP countries will be the abolishment of the Sugar Protocol. ACP countries that are dependent on this trade preference will be gravely affected. According to the Australian Bureau of Agricultural and Resource Economics (ABARE), the removal of the Sugar Protocol would be harmful for the employment prospects of poorly educated rural farm employees with possible negative social consequences in Fiji, a classic beneficiary of the Sugar Protocol. The loss of trade preference for sugar under remunerative prices may increase the poverty rate in Fiji from $21 \%$ to a staggering $80 \%$ (Reddy \& Yanagida 1998). A further example, preferential sugar contributes to $20 \%$ of Guyana's total GDP and over $50 \%$ of its agricultural production. Moreover, the sugar industry directly and indirectly employs 26,000 people who provide a living for 150,000 people out of a total population of 750,000 people (Guyana 2002). Guyana's sugar industry and the livelihood of the rural poor will most probably be threaten if Guyana is faced with competition from the massive and dominant sugar industry of Brazil. Thus, the rural poor will incur the bulk of the burden of structural change. This will be working against the United Nations Millennium Development Goal of reducing poverty and hunger.

There are arguments that the current preferential access to the EU market to selected developing countries is an inefficient instrument for supporting the economies of developing countries and there is uncertainty as to who gets the benefits (quota rents). It is argued that direct aid would be a better choice or it would generally serve the developing countries better to have free access for their products to the markets of developed countries (FOI 2002). Firstly, the choice of harming some developing countries by eliminating their trade preferences in order to increase market access for other developing countries should be avoided. Secondly, in contrast to the "banana regime," more than $95 \%$ of the income benefits from the high EU price for sugar are accrued to the developing countries and sugar traders are getting less than $5 \%$ of the income benefits ${ }^{3}$. In comparison, it is a common knowledge that a substantial part (sometimes as high as $70 \%$ to $80 \%$ ) of direct aids for developing countries are repatriated back to the donor countries and only a minor part reaching the developing countries. The question is how much of the aid money will finally reach the rural poor who are incurring the burden of structural change. Also, the preferential sugar system may be administratively burdensome, but the system is deeply entrenched ${ }^{4}$ that transaction costs are minimal due the learning experience of several decades. Finally, the theory of "survival of the fittest" will not help the least developed countries because these countries will not be able to compete with developing countries that have the infrastructure for sugar production. For example, Mozambique's sugar industry had been destroyed by flood and civil unrest. The sugar industry in Mozambique is only rebuilt after preferential market access for sugar has been given to Mozambique under the "everything but arms" trade concession. The question is how to motivate foreign direct investment into the least developed countries without the incentive of preferential market access in the developed countries.

The "everything but arms" initiative to eliminate duty and quota for sugar imports from the least developed countries is pressuring the EU to reform the EU sugar regime in order to avoid a major influx of sugar coming from the least developed countries. The lucrative EU sugar market will attract

\footnotetext{
${ }^{3}$ This information can be obtained by tracing the financial transaction and interviewing the top officials of EU refineries for raw sugar imports.

${ }^{4}$ Both the EU refineries and ACP countries have associations that manage the trade of preferential sugar.
} 
both genuine and fraudulent trade in sugar due to the high EU price for sugar compared to world market price. The "safeguard cases" involving the Overseas Countries \& Territories and Western Balkans countries have shown that the EU Commission is willing to make use of the safeguard measures stipulated in the preferential market access agreements. The emerging question will be whether it is politically correct to impose the safeguard measures on the least developed countries, when the EU has committed itself to open its market fully to the world's poorest countries or whether the EU will protect its domestic market due to internal pressures from the sugar industry and producers. The EU will have to find a solution to this complex situation.

Pressures from the multilateral agreement under the World Trade Organization to reduce import tariffs will instigate reform in the high support price for EU sugar. The EU will not be able to keep its border protection for sugar without lowering the support price for sugar. In addition, the use of export subsidies may be substantially reduced or eliminated, while quota sugar exports are heavily dependent on export subsidies. Thus, exports of quota sugar to the world market will not be possible without export subsidies due to the high EU price for sugar. Even the exports of non quota sugar (C sugar) are being challenged by Australia, Brazil, and Thailand in the WTO due to the issue of cross-subsidisation from the high EU price for quota sugar. The future multilateral agreement in liberalising agricultural trade and the dispute case on cross-subsidised sugar exports in the WTO will contribute to the magnitude of the forthcoming reform in the EU sugar regime.

The reform of the EU sugar regime will not be easy. The complexities in the interaction between the different trade agreements and the politically sensitive issues that involved trade preferences for sugar will be hotly debated both in the EU and also world-wide.

\section{References}

CEC (Commission of the European Communities) 2002. Enlargement and Agriculture: Successfully integrating the new Member States into the CAP - Sugar Sector (updated sugar production quotas according to the Copenhagen summit). SEC(2002) 95 final. Brussels: CEC.

EUROSTAT COMEXT. Internal and External Trade of the EU. Intra- and extra-EU trade CD-ROM: Supplement 2, 2001.

FAOSTAT. Food and Agriculture Organisation of the United Nations Statistical Databases. Available at http://apps.fao.org.

FOI 2002. The Byzantine EU Sugar Regime. Policy Brief 2, January 2002. Danish Research Institute of Food Economics. Available at http://www.foi.dk/engelsk/index.htm.

Guyana 2002. Guyana faces economic ruin if EU sugar regime challenge succeeds - Rohee tells WTO meeting in Geneva. Stabroek News, November 30, 2002. Available at http://www.landofsixpeoples.com/gynewsjs.htm.

Interactive TradeMap. Market Analysis Services. International Trade Centre UNCTAD/WTO. Available at Www.intracen.org/mas.

PC-TAS. Trade Analysis System on Personal Computer 1995-1999 Harmonized System. International Trade Centre UNCTAD/WTO, United Nations Statistics Division.

Reddy, M. \& Yanagida, J.F. 1998. Welfare Implications of Alternative Markets: A case study of Fiji's sugar industry. Journal of South Pacific Agriculture 15(1): 52-60. 